\title{
Investigating the Feasibility of Using Jatropha Curcas Oil (JCO) as Bio Based Rejuvenator in Reclaimed Asphalt Pavement (RAP)
}

\author{
Kabiru Abdullahi Ahmad ${ }^{1,2, *}$, Mohd Ezree Abdullah ${ }^{1}$, Norhidayah Abdul Hassan ${ }^{3}$, Nura \\ Usman $^{1}$, and Kamarudin Ambak ${ }^{1}$ \\ ${ }^{1}$ Faculty of Civil and Environmental Engineering, Universiti Tun Hussein Onn Malaysia, 86400 Parit \\ Raja, Batu Pahat, Johor, Malaysia \\ ${ }^{2}$ Faculty of Engineering, Department of civil engineering, Bayero University Kano, 3011 Kano State \\ Nigeria \\ ${ }^{3}$ Faculty of Civil Engineering, Universiti Teknologi Malaysia, 81310 UTM Skudai, Johor, Malaysia
}

\begin{abstract}
Reclaimed asphalt pavement (RAP) usage has increased recently due to the decreasing supply of liquid asphalt and concerns over adverse health effects when making use of petroleum-based/chemical recycling agents which increased the need for bio-based recycling agents designed to return the RAP binder to its original state. The objective of this study is to investigate the possibility of using jatropha curcas oil (JCO), which is a non-edible oil (do not compete with the food chain) that cannot be used for nutritional purposes due to the presence of anti-nutritional factors, such as phorbol esters, as a bio-base rejuvenating agent for aged bitumen. The physical properties and storage stability of the bio-oil, original bitumen, aged bitumen and rejuvenated bitumen were measured. The results of the investigation indicated that the bio-oil have potential to rejuvenate aged bitumen to condition that resembled the original bitumen, the use of the bio-oil show benefits from both health and environmental perspectives. Also the rejuvenated bitumen was found to be very stable in term of storage.
\end{abstract}

\section{Introduction}

Bitumen is the glue that binds aggregates together due to its complex, viscoelastic, rheological and non-crystalline nature (black or dark brown in colour) composed of heavy hydrocarbons with low dielectric constant $\left(\varepsilon^{\prime}\right)$, which is substantially soluble in carbon disulphide (CS2). Bitumen is a low less material with loss tangent, $\tan \delta\left(\varepsilon^{\prime \prime} / \varepsilon^{\prime}\right)<0.5$, exhibits both adhesive and waterproofing characteristics, and microwave permittivity (dielectric constant, $\varepsilon^{\prime}$ ) value ranging from 2-7 depending on the grade of the bitumen and asphaltenes content of distilled products obtained from the oil refining process. Bitumen been a product obtained from the oil refining process. Though it is used as a

*Corresponding author: kabiruaahmad@gmail.com 
binder for flexible pavement all over the world, it has severe environmental impacts. Bitumen is non-hazardous at room temperature but when heated at 165-200 C, it becomes toxic. Consequences, such as environmental degradation, depleting petroleum reserves and price-spiking, led researchers to explore alternative sources of obtaining binder for pavement. In the world market the price of petroleum is constantly increasing as the consumption level spikes. The price of petroleum crude oil was $\$ 61.95$ per barrel in 2008 but in 2013 it had gone up to $\$ 97.98$ per barrel $[1,2]$. This in turn has led to an increase in the price of asphalt. Because of the rapid increasing demand for natural petroleum products such as bitumen and its unstable price and also it's severe effect on our environment as well as the health of pavement workers. Researchers, Engineers and pavement industries need to find new products and materials[3]. They must not just rely on traditional routes, but need ingenuity to develop new ideas to use and reuse resources in different ways, and to look for new solutions to old problems of high demand for liquid asphalt is increasing rapidly and petroleum oil reserves becoming depleted. [4].Researchers and pavement industries have been seeking of new technology and approaches to reduce the use of petroleum asphalt. Using alternative materials is one of the most effective and environmentally friendly ways to solve this problem. Some positive approaches were applied, such as the recycling of asphalt pavement materials. Over the years, considerable experience has been gained; today recycling methods are also considered for heavy trafficked roads, and the recycling ratio may be close to $100 \%$. The use of RAP have increase remarkably, this in turn has led to an increase in demand of rejuvenators. [5, 6].Bio resources researchers and pavement engineers have investigated a range of different bio oils such as waste cooking oil, waste engine oil as rejuvenating agents designed to return the RAP binder to its original state[7]. The result of the investigation indicate that by utilizing waste engine oil (WEO) and waste cooking oil (WCO) as rejuvenating agents have revive the aged bitumen to a condition that resembles $60 / 70$ and $80 / 100$ penetration grade bitumen respectively[8, 9]. As a result of increasing emphasis on pavement sustainability and promoting the use of alternative resources as binder and also the success achieved in using WEO and WCO powered the idea of using jatropha curcas oil (JCO) which is a non-edible oil (do not compete with the food chain) that cannot be used for nutritional purposes due to the presence of anti-nutritional factors, such as phorbol esters as a bio-base rejuvenating agent for aged bitumen. The novelty of this paper is using jatropha curcas oil (JCO) as a bio-based recycling agent in aged bitumen. The main objective of this study was to investigate the possibility of utilizing JCO as a bio-based recycling agent through physical properties test and storage stability properties of asphalt binder. The potential use of non-edible bio-oil as a bio-base RAP rejuvenator is an attractive way to increase the longevity and enhance the performance of asphalt pavements.

\section{Material and experimental procedure}

\subsection{Asphalt binder}

In this study, artificial reclaimed bitumen was obtained by subjecting bitumen grade 60/70 to long-term aging by means of the Pressure Aging Vessel equipment. After the aging 
process was completed, the artificial reclaimed bitumen was tested to using penetration test to determine the group of the aged bitumen. The aged bitumen based on the penetration test was found to $40 / 50$ penetration grade. The choice to use a laboratory aged bitumen rather than a bitumen directly extracted from milled material does not limit the general validity of this study as each extracted bitumen would have its own characteristics and could be considered in any case not exhaustive of the all possible conditions, analogously to the laboratory aged one. Moreover, the laboratory aged bitumen is always reproducible for further investigation or comparative purpose.

\subsection{Bio-oil}

The bio-oil used in this study is hot water extracted jatropha curcas oil (JCO) which is a non-edible oil that cannot be used for nutritional purposes due to the presence of antinutritional factors, such as phorbol esters. Before adding bio-oil into the control asphalt, the physiochemical properties of bio-oil were investigated.

\subsection{Materials preparation}

Aged bitumen 40/50 penetration grade asphalt was uniformly heated first in a temperatureregulated heating mantle and continuously stirred using a high shear mixer. Then, $0 \%, 1 \%$, $3 \%, 5 \%$ bio-oil were added into aged bitumen $40 / 50$ penetration grade asphalt. When test temperature reached $155^{\circ} \mathrm{C}$, and then blended for $25 \mathrm{~min}$ by high shear mixer with a speed of 600rpm to achieve a homogeneous mixing state $[4,8,10,11]$.

\subsection{Experimental methods}

Firstly, physiochemical properties investigation of the bio-oil (JCO) was carried out. Then, the physical properties of both the control and the rejuvenated aged bitumen were studied. Viscosity test, ductility, storage stability and temperature susceptibility in accordance with ASTM D36, D5, and D 4402, respectively.

\section{Results and discussion}

\subsection{Physical properties of jatropha curcas oil}

In this case Table 1 shows that jatropha curcas have low iodine below 100, pour point of $4^{\circ} \mathrm{C}$ and cloud point of $14^{\circ} \mathrm{C}$, indicating that the oil is non-dry oil can perform satisfactorily even in cold climatic conditions. A low peroxide value, as seen increases the suitability of the oil. For a long-time storage due to a low level of oxidative and lipolytic activities. Also the lower the oil viscosity, the easier it is to pump and atomize, and achieve finer results. In addition, Oils with flash point above $66^{\circ} \mathrm{C}$ are considered as safe oils. With a flash point of $150^{\circ} \mathrm{C}$, Jatropha curcas oil can prevent auto ignition and fire hazard at high temperatures during transportation and storage.

\subsection{Chemical composition of jatropha curcas oil}

Table 2 shows the presence of high amount of polyunsaturated fatty acids (linoleic acid) in JCO makes it a great potential for oleo chemical application Such as surface coating industries and bio lubricant base oil applications whereas the high amount of monounsaturated fatty acid can find an application as a biodiesel feed [12]. 
Table 1. Physical properties of Jatropha curcas seed oil.

\begin{tabular}{ll}
\hline Property & Value \\
\hline Boiling point & $124^{\circ} \mathrm{C}$ \\
pH & 5.2 \\
Free fatty acids & $0.0718 \mathrm{mg} \mathrm{KOH} \mathrm{g-1} \mathrm{oil}$ \\
Specific gravity & 0.9186 \\
Flash point & $230^{\circ} \mathrm{C}$ \\
Cloud point & $14^{\circ} \mathrm{C}$ \\
Saponification value & $155 \mathrm{mg} \mathrm{KOH} \mathrm{g}-1$ oil \\
Peroxide value & $7.20 \mathrm{meq} \mathrm{g}-1$ oil \\
Iodine value & $51.27 \mathrm{~g} 100 \mathrm{~g}-1$ oil \\
Pour point & $4^{\circ} \mathrm{C}$ \\
Density at $27^{\circ} \mathrm{C}$ & $0.725 \mathrm{~g} \mathrm{~cm}-$ \\
Acid value & $0.1428 \mathrm{mg} \mathrm{KOH} \mathrm{g-1} \mathrm{oil}$ \\
Viscosity & $8.2 \mathrm{cst}$
\end{tabular}

Table 2. Shows the chemical compositions of jatropha curcas oil

\begin{tabular}{lcl}
\hline \multicolumn{2}{c}{ Fatty acid composition } & $\mathbf{( \% )}$ \\
\hline Palmitic & (C16:0) & 11.3 \\
Linoleic & $(\mathrm{C} 18: 2)$ & 47.3 \\
Oleic & $(\mathrm{C} 18: 1)$ & 12.8 \\
Stearic $\quad(\mathrm{C} 18: 0)$ & 17 \\
Palmitoliec & $(\mathrm{C} 16: 1)$ & 0.7 \\
Linolenic & $(\mathrm{C} 18: 3)$ & 0.2 \\
Arachidic & $(\mathrm{C} 20: 0)$ & 0.2 \\
Margaric & $(\mathrm{C} 17: 0)$ & 0.1 \\
Myristic $\quad(\mathrm{C} 14: 0)$ & 0.1 \\
Saturated & & 21.6 \\
Monounsaturated & 45.4 \\
Palmitic & $(\mathrm{C} 16: 0)$ & 11.3
\end{tabular}

\subsection{Physical properties of bitumen}

Penetration and softening tests are an empirical tests used to evaluate the consistency of the binder i.e. to measure of the resistance offered by a fluid to continuous deformation when it is subjected to shearing stress in accordance to with ASTM D[13-15].

The physical properties of the rejuvenated binder are illustrated in Fig. 1 and 2 with a decrease in softening points and an increase in penetration values resulted from adding different percentages $(0,1 \%, 3 \%$, and $5 \%)$ of JCO by weight of the aged bitumen will soften the bitumen.

According to the results which have been presented in Fig. 1, the addition of $3 \%$ JCO by weight of bitumen into the aged bitumen penetration grade 40/50 will increase the penetration value that resembles the original $80 / 100$ bitumen with the penetration value of 85.5. While in Fig. 2 the softening point of the aged bitumen was decrease to a value that is equivalent to original $80 / 100$ bitumen. 


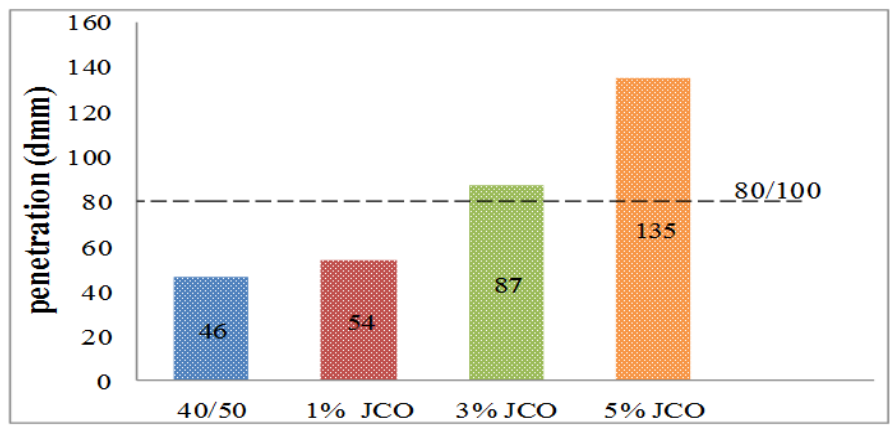

Fig. 1. Penetration results of $40 / 50$ binder blended with JCO.

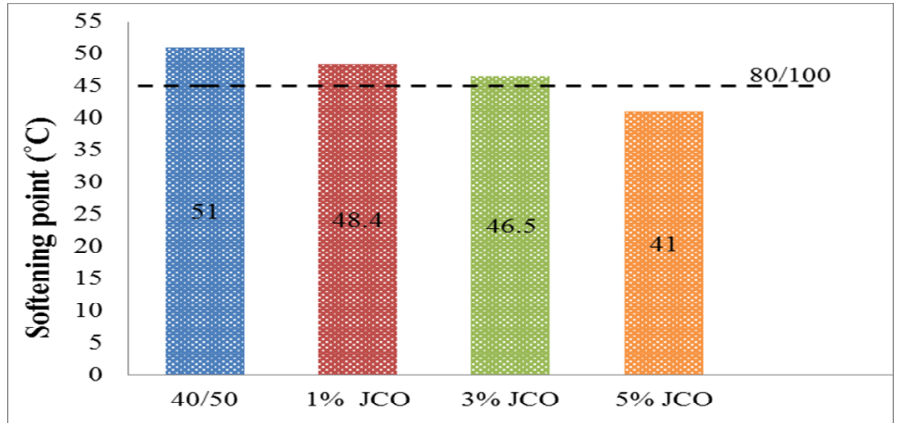

Fig. 2. Softening results of 40/50 binder blended with JCO.

\subsubsection{Ductility test}

Ductility test was used to evaluate the asphalt binder ductility by stretching a standard-sized briquette of asphalt binder to its breaking point in accordance to ASTM D113[16]. According to the results which have been presented in Fig. 3, it can be concluded that the ductility of the aged bitumen was observed to decrease with increase in the percentage of JCO.

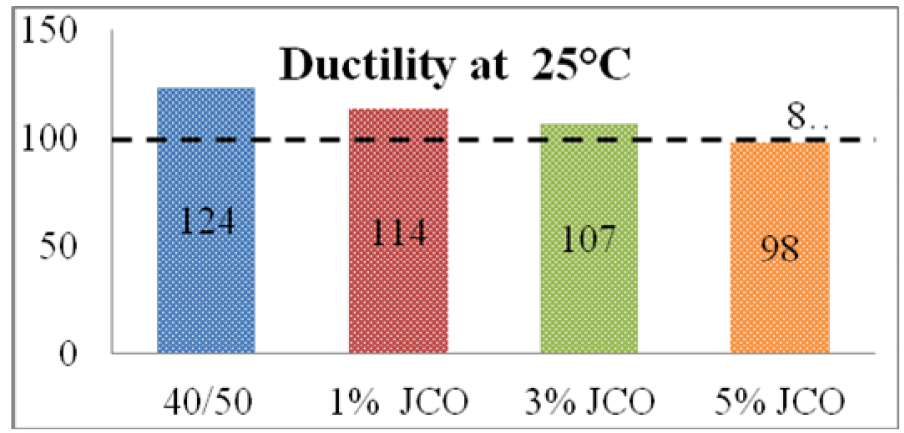

Fig. 3. Ductility results of 40/50 binder blended with JCO.

\subsubsection{Storage stability}

According to the results which have been presented in Fig. 4, it can be seen that the difference between softening point of the top and the bottom sections of aged bitumen 
(40/50) was $0.2^{\circ} \mathrm{C}$. Meanwhile, the result of aged bitumen rejuvenated with different percentages of $\mathrm{JCO}$ are $0.55^{\circ} \mathrm{C}(1 \%), 0.5^{\circ} \mathrm{C}(3 \%)$ and $0.45^{\circ} \mathrm{C}(5 \%)$. thus, It can be seen that all rejuvenated binder samples are less than $2.2^{\circ} \mathrm{C}$ and these could be regarded as storage stable blend.

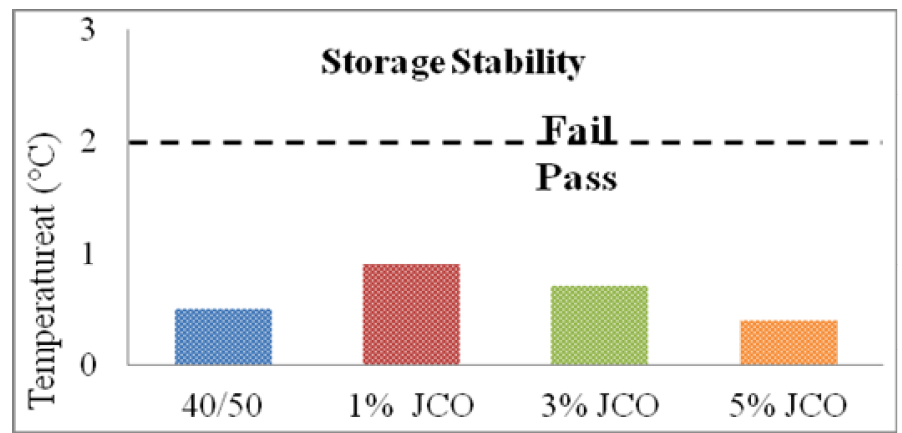

Fig. 4. Storage stability results of 40/50 binder blended with JCO.

\subsubsection{Viscosity test}

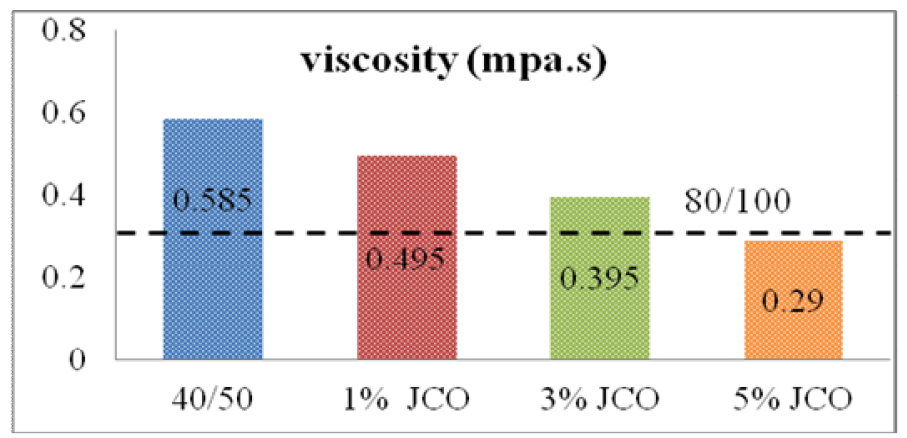

Fig. 5. Viscosity results of 40/50 binder blended with JCO.

According to (ASTM D4402) viscosity (degree of fluidity) grading, higher the grade, stiffer the bitumen[17]. Viscometer test was used to evaluate the difference in viscous behaviour's aged bitumen rejuvenated with different percentages of JCO. The temperatures selected for RV test was $135^{\circ} \mathrm{C}$ which is usually applied to measure the workability of the bitumen, according to Superpave specifications. From the rotational viscosity plots shown in Fig. 3, it can be seen that the aged bitumen has the highest value. However, the viscosity value obtain on the addition of 5\% JCO into the aged bitumen resembles the viscosity of original penetration $80 / 100$ bitumen but $3 \%$ JCO shows a higher viscosity than original penetration $80 / 100$ even though its lower than that of the aged bitumen $(40 / 50)$.

\subsubsection{Temperature susceptibility}

Temperature susceptibility is defined as the change in the consistency parameter as a function of temperature. The temperature susceptibility of the modified asphalt binder samples was calculated in terms of penetration index (PI), using the results obtained from penetration and softening point tests according to proposed equation of shell bitumen handbook[18]. 


$$
P I=\frac{1952-500 \log \left(\text { pen at } 25^{\circ} \mathrm{C}\right)-20(\mathrm{sp})}{50 \log \left(\text { pen at } 25^{\circ} \mathrm{C}\right)-\mathrm{sp}-120}
$$

The PI value of virgin bitumen reduces after aging. As illustrated in Fig. 5, PI value of aged bitumen increases with the addition of JCO. The higher the percentage added, the higher the PI value increases which indicate lower thermal susceptibility. Asphalt mixtures containing bitumen with higher PI are more resistant to low temperature cracking as well as permanent deformation (rutting)[13].

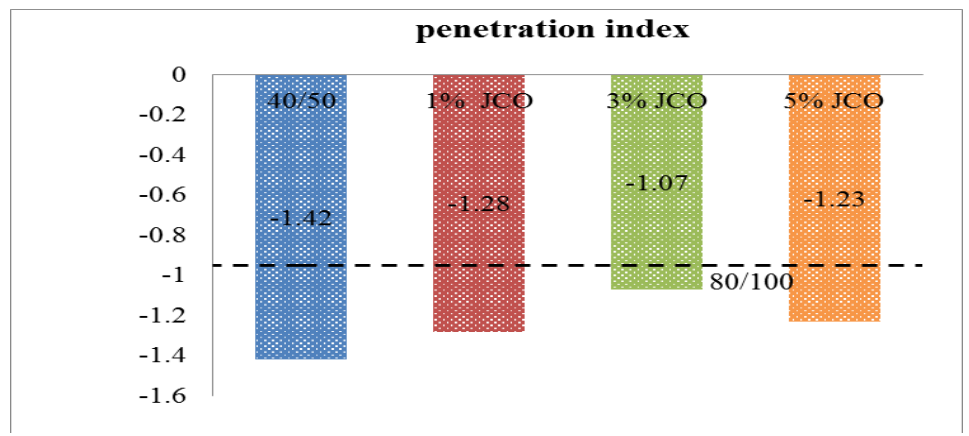

Fig. 6. Temperature susceptibility results of $40 / 50$ binder blended with JCO

\subsubsection{Dynamic shear rheometer}

Fig. 7 is a plot of the $\mathrm{G}^{*} / \mathrm{Sin}(\delta)$ parameters obtained from the DSR test results. These results are for the 40/50 binder that was then blended with $1 \%, 3 \%$ and $5 \%$ and JCO [16, 19]. The control binder, shown in blue (40/50) have an upward shift for all data points, and had an overall of PG 76, indicating the binder stiffness. The binder blend with $3 \%$ JCO performed almost identically to the original binder by reducing the PG to 64 , as indicated by the $\mathrm{G}^{*} / \mathrm{Sin}(\delta)$ less than the specification of $1000 \mathrm{~Pa}$ at $64^{\circ} \mathrm{C}$. Statistically, it can be seen that the coefficient of determination $\left(\mathrm{R}^{2}=0.98\right)$ shows that the rejuvenated binder is $98 \%$ similar to original $80 / 100$ bitumen. The addition of JCO into the aged bitumen led to a drop in high temperature penetration grade, which means the rutting resistance is moving toward the rejuvenated bitumen.

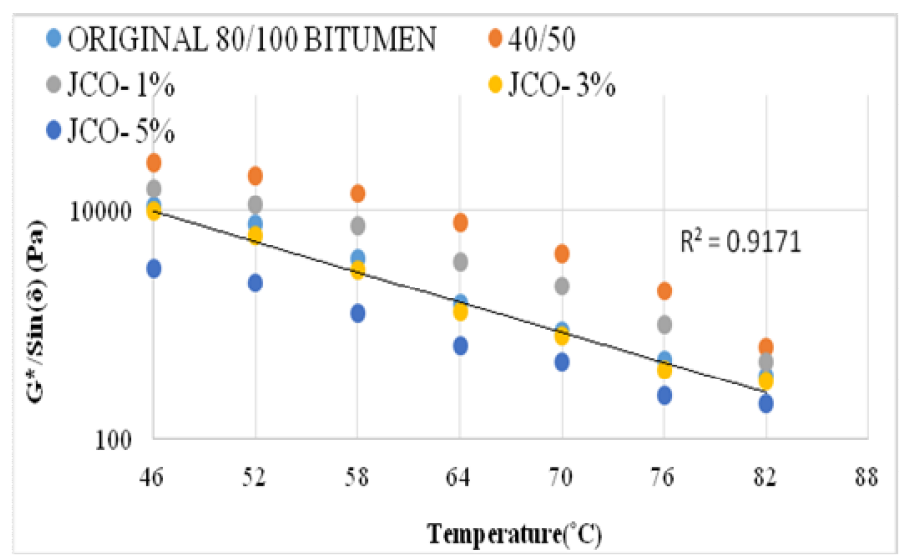

Fig. 7. DSR results of $40 / 50$ binder blended with JCO 


\section{Conclusion}

As mention earlier, the main purpose of this study is to investigate the feasibility of JCO as a bio-based recycling agent through physical tests and storage stability properties of bitumen. From these test results, the following can be concluded. (1) The increase in penetration grade due to aging corresponds to an increase in stiffness and rutting resistance. With subsequent percentages of oil added, that stiffening was reduced and ultimately the bitumen was softened.(2) Results showed that $3-4 \%$ JCO has the ability to counteract the stiffening of the $40 / 50$ aged bitumen to a value that is equivalent to original $80 / 100$ bitumen. (2) The increase in softening point and decrease in penetration of the aged bitumen shows the effectiveness of JCO in reducing age-hardening. (4) PI value increases which indicate lower thermal susceptibility. Asphalt mixtures containing asphalt binder with higher PI are more resistant to low temperature cracking as well as permanent deformation (rutting) (5) Storage stability tests indicated that the rejuvenated bitumen is very stable.(6) Statistically, it can be seen that the coefficient of determination $\left(R^{2}=0.91\right)$ shows that the rejuvenated binder is similar to original 80/100 bitumen. Above all the result shows the potential of JCO as a bio-base rejuvenator for recycling bituminous mixtures in order to reduce the construction and maintenance cost of flexible pavement.

Special thanks to Office for Research, Innovation, Commercialization and Consultancy Management (ORICC) and centre for graduate studies Universiti Tun Hussein Onn Malaysia (UTHM) for funding this project.

\section{References}

[1] Bioenergy, Retrieved 2015. http://www.avellobioenergy.com /en/products/ bioasphalt_binder/

[2] M.M.A. Azziz, M.T. Rahman, M.R. Hainin, W.A.W.A. Bakar, An overview on alternative binders for flexible pavement, Construction and Building Materials, 84, 315-319 (2015)

[3] N. Usman, M.I. Mohd Masirin, A.K. Abdullahi, W. Anwaruddin Ahmed, Reinforcement of asphalt concrete mixture using recycle polyethylene terephthalate fibre, Indian Journal of Science and Technology, 9(46), (2016)

[4] J. Peralta, M.A. Raouf, S. Tang, R.C. Williams, Bio-renewable asphalt modifiers and asphalt substitutes, Sustainable Bioenergy and Bioproducts, Springer, 89-115 (2012)

[5] Z. You, J. Mills-Beale, E. Fini, S.W. Goh, B. Colbert, Evaluation of low-temperature binder properties of warm-mix asphalt, extracted and recovered RAP and RAS, and Bioasphalt,. Journal of Materials in Civil Engineering, (2011)

[6] M. Zaumanis, R.B. Mallick, R. Frank, 100\% recycled hot mix asphalt: A review and analysis. Resources, Conservation and Recycling, 92, 230-245 (2014)

[7] M. Zaumanis, R.B. Mallick, R. Frank, Use of rejuvenators for production of sustainable high content RAP hot mix asphalt, XVIII International Baltic Road Conference, Vilnius, (2013)

[8] M. Zargar, E. Ahmadinia, H. Asli, M. R. Karim, Investigation of the possibility of using waste cooking oil as a rejuvenating agent for aged bitumen, Journal of Hazardous Materials, 233, 254-258 (2012)

[9] H. Asli, E. Ahmadinia, M. Zargar, M.R. Karim, Investigation on physical properties of waste cooking oil-Rejuvenated bitumen binder, Construction and Building Materials, 37, 398-405 (2012) 
[10] E.H. Fini, E.W. Kalberer, A. Shahbazi, M. Basti, Z. You, H. Ozer, Q. Aurangzeb, Chemical characterization of biobinder from swine manure: Sustainable modifier for asphalt binder, Journal of Materials in Civil Engineering, 23(11), 1506-1513 (2011)

[11] H. Wen, S. Bhusal, B. Wen, Laboratory evaluation of waste cooking oil-based bioasphalt as an alternative binder for hot mix asphalt, Journal of Materials in Civil Engineering, 5(10), 1432-1437 (2012)

[12] K.A. Ahmad, N. Abdul Hassan, K. Ambak, A. Musbah, N. Usman, S.K. Abu Bakar, Extraction techniques and industrial applications of jatropha curcas, Jurnal Teknologi, 78, 53-69 (2016)

[13] M.E. Abdullah, K. Ahmad Zamhari, N. Nayan, M. Hermadi, M.R. Hainin, Storage stability and physical properties of asphalt modified with nanoclay and warm asphalt additives, (2011)

[14] ASTM-36, Standard Test Method for Softening Point of Bitumen (Ring-and-Ball Apparatus), West Conshohocken, (2009)

[15] ASTM-D36, Standard Test Method for Softening Point of Bitumen (Ring-and-Ball Apparatus), American Society for Testing and Materials, (2009)

[16] M.E. Abdullah, K.A. Zamhari, M.R. Hainin, E.A. Oluwasola, N.A. Hassan, N.I.M. Yusoff, Engineering properties of asphalt binders containing nanoclay and chemical warm-mix asphalt additives, Construction and Building Materials, 112, 232-240 (2016)

[17] ASTM-D4402, Standard Test Method for Viscosity Determinations of Asphalts at Elevated Temperatures Using a Rotational Viscometer, American Society for Testing and Materials, (2002)

[18] J. Read, D. Whiteoak, The shell bitumen Handbook, Thomas Telford, (2003)

[19] ASTM-D7175, Standard Test Method for Determining the Rheological Properties of Asphalt Binder Using a Dynamic Shear Rheometer (DSR), American Society for Testing and Materials, (2005) 